\title{
Hierarchical Research on Pragmatic Failures of Apology in Public Events Under the Vision of New Media
}

\author{
Kiwi Zhu, Rose Mary \\ Zhejiang University of Finance and Economics, Hangzhou, China
}

\begin{abstract}
Under the new media, the dissemination and the influence of public events are often far more profound than traditional media. Therefore, it has gained a high degree of social attention. We take the apology mistakes in public events as an example, sort out the types and causes of the mistakes into a context, and propose some relevant strategies.
\end{abstract}

Keywords: public events, apology, pragmatic failure

\section{Introduction}

What is the apology speech act? Holmes (1990) believes that an apology has a social function, and that the speaker recognizes the mistakes he made in order to take care of the face of the listener. In this way, the social relationship between the speaker and the listener is restored. Li Jun (2007) analyzed from the perspective of pragmatics and considered that apology speech acts belonged to the type of remedial speech act and had discourse function. Based on this, he divided the apology speech act in Chinese into four parts: calling language, explicit apology, fact statement, and apology assisting strategy. From the perspective of cross-cultural analysis, Blum and Olshtain (1984), Su Meiling (2011), Zhao Yingru (2018), and others believed that apology speech behavior has cultural differences. Faced with an endless stream of "apologies" in the context of the entire media, we believe that it is imperative to do a case study.

\section{Pragmatic Standards and Error Characteristics of Apology in Public Events}

In light of some people's views, we know that apology speech acts are a salvative speech act that has certain cultural differences. But it also adheres to the principles of cooperation and courtesy. It can make the relationship between the speaker and the listener more harmonious. In the context of apology, the speaker and the recipient often form a pair of corresponding pragmatic subjects.

According to the definition and content analysis of the apology speech act, combined with the public events, we summarizes the types of pragmatic failures in public events as: break timeliness mechanism, mistakes in the construction of discourse platform, mistake that deviates from both sides of pragmatics.

Kiwi Zhu, Graduate student, Chinese name is Xiaofei Zhu, school of humanities and communication, Zhejiang University of Finance and Economics, Hangzhou, China.

Rose Mary, Graduate student, Chinese name is LiudanQiu, school of humanities and communication, Zhejiang University of Finance and Economics, Hangzhou, China. 


\section{Break Timeliness Mechanism}

The timeliness mechanism usually requires the speaker to perform an apologizing speech act on the listener for the first time. In public events, the speech act also needs to cover the specific efforts made by the speaker. In May 2018, Didi company indirectly caused a female passenger's death due to poor system management. The matter became a public event at the time. With the spread and interaction of information, its social attention has become increasingly prominent, and it has long occupied the hot search list of major social media. However, within five days of the passenger's disappearance, Didi company did not report or apologize for the disappearance and murder of the passenger. On May 11, 2018, “Ping An Zhengzhou” issued a police notice. The next day, Didi company released relevant apology information. From the perspective of timeliness, the timeliness of an apology has not been reflected.

When we browsed the comments, we found out that because the company did not apologize timely, it directly led to the dissatisfaction of the people. Although we saw Didi's explicit apology speech act, we did not find out how the platform did its best to prevent the specific efforts to regenerate such situations. Therefore, Didi does not really pay attention to this management mistake. The company's apology speech act has obvious pragmatic mistakes that violate the validity principle and is not convincing to the masses.

Example 1: Didi company once again has a murder! The girl from Wenzhou was killed by dripping the taxi. In August of the same year, a girl from Yueqing, Wenzhou, was killed by the taxi of the murderer. In the context of new media, the news hit rate had been rising and stayed at the top of Sina Weibo's hot search list for many days. The management of Didi has become a public event. Under pressure from public opinion, Didi issued an apology statement the next day. In this statement, the author found that Didi has used apologetic language such as address, cohesion, sincerity language, explicit language facts, remedial measures. Although the discourse entity has been satisfied, from the analysis of the results of the apology, we find that such an apology is still unable to calm the public's mood. Didi's apology is not "efficient".

\section{Mistakes in the Construction of Discourse Platform}

This type of error is usually manifested by the speaker not using the relevant apology to construct a language or platform build error, such as, not directly facing the caller, not using effective platform media, salutation language, cohesive language, and remedial measures.

Example 2: In 2017, Zhou from Guangxi was arrested by the public security organs for theft.

In the face of the reporter's visit, Zhou did not apologize to the public for the mistakes he made. When the reporter asked him, he replied that "it is impossible to work as a part-time worker. It is impossible to work in my life, and only stealing things can sustain life”. From his words, we did not find that it used relevant apology words or sentences. His words became popular because of its reproducibility, and became a public event at one time. Many netizens also used the ridiculous discourses such as "To do sth is impossible, and it is impossible to do sth in my whole life". It can be seen that the apology of the public apology has a profound impact on the people.

Example 3: In July 2018, Changsheng Biotech Co., Ltd., was rumored to be a public event because it was diagnosed with a production problem vaccine. After the incident, Changsheng Biotech Co., Ltd., responded to the Shenzhen Stock Exchange and said, “At present, the company’s production workshop has been discontinued.... We are very self-blaming and embarrassed about the incident, and we will again vaccinate and invest in you. The 
company expressed deep apologies. The company will take the lead in ensuring the safety of the vaccine”.

In this apology, Changsheng Company, despite salutation language, cohesive language, explicit language facts, still violates the principle of discourse construction. After the incident, Changsheng Biotech did not apologize through the mass media platform, and most of the victims could not see such an apology. In this case, the pragmatic subject did not reach the "saturated" state, and the pragmatic subject, the discourse entity, and the context could not penetrate each other, and the creation of the sincere context failed.

\section{Mistake That Deviates From Both Sides of Pragmatics}

When considering how to organize an apology, the speaker should always be prepared to switch to the role of the recipient and stand in the same position as the recipient. This requires the speaker to apologize and act in a "cooperative" manner when conducting an apology.

The cooperative mechanism is a pragmatic guarantee of apology speech behavior and a direct strategy for the speaker to express emotions. Recently, we selected a popular public event for analysis.

Example 4: Chinese Embassy in Sweden: Do not accept the false "apology" of Swedish TV stations. In September 2018, Chinese tourists suffered violent treatment in Sweden, which became a public event in Chinese society. Relevant personnel of the Chinese Embassy negotiated with Sweden on this matter. Since then, the Swedish news program has responded to the "apology" request to play related videos. In the video, we can see that the female anchor constantly uses the slapstick tone to repeatedly emphasize the ironic language. These so-called "apologies" are very different from the apologies that the hearers demand. In the video, the anchor violated the decent and humble guidelines, over-exaggerated and fabricated the truth, and damaged the image of the Chinese. At the end of the video, the female anchor smiled and said, “But if you don't perform well, we will hit you...” This kind of threatening language is not only contrary to the "apology" demanded by the Chinese, but also threatens the positive face of the Chinese directly. Afterwards, the relevant responsible person said that the original intention of arranging such a program was to apologize, and it was the cultural differences that led to misunderstanding. The author believes that although speech acts are culturally different, the "apology" such as Sweden deliberately deviates from the coordination mechanism and is obviously flawed, which is quite different from the apology expected by the public. The principle of collaboration is at the heart of the apology speech act, and the "apologize" with ulterior motives in the "Swedish News" program is ultimately not recognized by the public.

\section{Analysis of the Causes of Apology Pragmatic Failures in Public Events}

According to the classification of apology pragmatic mistakes in the previous article, combined with linguistic knowledge, we believe that the reasons for apology pragmatic errors in public events can be summarized as follows.

\section{Communicative Purposes in a Specific Context}

The purpose of communication is the core of communication. The apology speech act contains communicative behavior, and the apology speech act is the expression of the speaker's psychological state. Wang Jianhua (2002) believed that the purpose of communication is a context in which the purpose of speech restricts the choice of discourse form. At the same time, the discourse form directly affects the realization of discourse 
purpose. In a specific context, the relevant speaker will adopt the corresponding method in order to achieve the effect of the words and the purpose of communication. The above-mentioned "Swedish News" column was a special video, deliberately violating the politeness principle and collaboration principle. The purpose of communication is not to express embarrassment, but to wear a "apology cloak", causing attention and then "insulting China” again.

\section{Subjects Who Are Focused on His Own Positive Face Extremely}

In order to maximize their own positive face, the speaker often adopts an apology that begs the question. The main performances are as follows: (1) mechanism of deviation from discourse significance: The apology activist does not directly state his own mistakes, and euphemistically express one's own mistakes in apology and speech acts. (2) Time-breaking mechanism was adopting a "delayed" strategy, avoiding the turmoil of public opinion, or not making specific remedial measures to ensure the maximization of its own interests.

\section{Lack of the New Media Platforms}

We believe that new media is a relative concept, including the "two micro-net" (WeChat, Weibo, official website) under the Internet. The new media promote the dissemination and development of information, and various public events that are constantly emerging are constantly reflected in the eyes of the public. However, in the public event apology speech act, the relevant speaker failed to correctly use the relevant popular new media platform, which led to apology and pragmatic failure. For example, after Changsheng Biotech was found to have a problem vaccine incident, it did not apologize on the official Weibo or WeChat. Instead, it replied to the Shenzhen Stock Exchange on the official website to apologize for the vaccine incident. The apology information was unclear and the apology speech act was wrong.

\section{Coping Stategies to Apologizing Pragmatic Mistakes}

\section{Grasp the Initiative of Discourse and Build a Harmonious Discourse Platform}

When implementing apology speech acts, we should pay more attention to the construction of a harmonious discourse platform. So how to build a harmonious discourse platform? Scientific research shows that apologies do not need to focus solely on what they do. This brings us a way of thinking-more emphasis should be placed on late effects when building a harmonious discourse platform. The apology implementer should also include remedies and post-planning in the conduct of apology speech acts. In combination with the Didi's apology mistakes, the responsible person responsible for the apology can grasp the initiative of the discourse, pay attention to the construction of a harmonious discourse platform, maximize the "profit" to accept the words, and properly take remedial measures. Then, the tragedy may not happen one after another.

\section{Make Full Use of the New Media Platforms}

According to the 42nd "China Internet Development Status Report” released by CNNIC on August 20, 2018, the number of Chinese netizens reached 802 million, and mobile Internet users accounted for $98.3 \%$, of which Weibo users exceeded 400 million. WeChat users exceeded one billion.

The number of users of the new media platform is increasing, which means that if the apology speech mistakes occur, the relevant pragmatic subject will be hurt again. A reasonable apology for using the popular new media platform not only meets the validity principle, but also alleviates the pain or anger of the recipient. After a 
negative public event occurs, the relevant responsible person should promptly adopt relevant strategies to stabilize the situation, reflect on itself, explain and apologize on relevant matters, and appease the sentiment of the recipient. Using popular new media platforms, such as Sina Weibo, Tencent Weibo, WeChat, official website, and other popular online platforms, observe and control the rudder paddles and conduct apology speech acts to make apologies more sincere and effective.

\section{Build a Professional Language Public Relations Team}

As a language of apology in public events, it should not only be clear, normative, but also decent and sincere. It requires the subject should choose the language in the relevant context. How to arrange the language, and how to integrate its sincere attitude into the language of apology, these are all need to be considered. Apologizing language behavior in public events is not only a manifestation of personal wisdom, but also a manifestation of team wisdom. Therefore, it is imperative to create a professional and efficient language public relations team.

\section{Conclusion}

From the three types of pragmatic failures in public events under the new media perspective, we summarize the relevant reasons and coping strategies. Apologizing speech acts as an auxiliary and remedial role is a compensatory behavior to make up for previous mistakes. However, in public events, how the relevant pragmatic subjects skillfully use language rhetoric, avoid "second mistakes", and rationally use apology language strategies to exercise apology and speech acts still has a long way to go.

\section{References}

Holmes, J. (1990). Apologies in Newzealand English. Language in Society, 2, 237-257.

Kulka, B., Shoshana, \& Olshtain, (1984). Requests and apologies: A cross cultural study of speech act realization patterns ( CCSARP). Applied Linguistics, 5, 196-213.

Li, J. (2005). Analysis of discourse patterns and pragmatic features of apology behavior. Language teaching and research, 1, $11-19$.

Su, M. L. (2011). A comparative study of Chinese-English apology speech behavior (Master's Thesis, Shaanxi Normal University.).

Wang, J. H. (2002). A study of modern Chinese context (p. 191). Zhejiang: Zhejiang University Press.

Zhao, Y. R. (2018). A comparative study on the social cognition of speech act of political apology in China and America (Master's Thesis, Dalian Foreign Studies University.). 